\title{
From Life-Threatening Experiences to Ideas of Rescue: Coping with "Trajectories of Suffering" in Adult Acute Leukaemia Survivors
}

\author{
Viktoria Heine $^{1 凶}$, Fritz Schütze ${ }^{2}$, Michael Koehler ${ }^{3}, \&$ Joerg Frommer ${ }^{1}$
}

\begin{abstract}
We investigated the illness records and life stories of 17 leukaemia survivors using narrative autobiographical interviews. Audio tapes were transcribed and analysed according to qualitative methodology. Using the sociological concept of "trajectory of suffering" (TOS) as a means of analysis we focused on the survivors' mechanisms of psychosocial adaptation including integration of disease-related experiences as part of their autobiographical narration. Verbal data show how the diagnosis pulls affected people out of their everyday life from healthy, strong and with plans for the future to seriously ill, weak and facing death, and thus suspends their self-confidence and social action competence. Analysing the interview transcripts we found six categories of coping with TOS: (1) personal meaningful nourishments, (2) challenging experience with significant others, (3), courage to persevere, (4) family support, (5) dramatic family events, and (6) dreams. The results of our study demonstrate that the cancer is still a dark shadow over the lives of all survivors. They are discussed in the context of coping theory postulating creativity as an up to now underestimated resource of coping behaviour. As a consequence it seems to be vital that medical staff should recognize and discuss these individual needs and feelings of their patients in daily clinical practice.
\end{abstract}

Keywords: psycho-oncology, cancer survivors, leukaemia, qualitative research, biography, coping

Acute leukaemia is a rapidly proceeding malignant disease of the haemopoietic system. Hence, the diagnosis of acute leukaemia presents a sudden vital threat for the patient, an attack to his or her very existence. According to the nature of this disease, treatment starts immediately (Estey \& Kantarjian, 2005). During the treatment, chemotherapies and repeated hospitalisations are necessary for months. Despite intensive

\footnotetext{
${ }^{1}$ Otto-von-Guericke-University, Department of Psychosomatic Medicine and Psychotherapy, Leipziger Str. 44, 39120, Magdeburg, Germany.

2 Otto-von-Guericke-University, Institute of Sociology, Zschokkestraße 32, 39104 Magdeburg, Germany.

${ }^{3}$ Otto-von-Guericke-University, Department of Haematology and Oncology, Leipziger Str. 44, 39120, Magdeburg, Germany.

Correspondence concerning this article should be addressed to Prof. Dr. med. Joerg Frommer, M.A., Otto-vonGuericke-University, Department of Psychosomatic Medicine and Psychotherapy, Leipziger Str. 44 - 39120 Magdeburg, Germany.E-mail: joerg.frommer@med.ovgu.de
}

therapy, most of the adult patients die: merely $30-40$ percent of the patients younger than 60 with acute leukaemia survive (Buechner et al., 2009). Moreover, a high illness and therapy-related morbidity for all patients as well as a vital threat exists.

The history of research on subjective conceptualizations of the causes of illness and treatment expectations in cancer patients is closely linked with the history of interview-based qualitative research itself. Data of open interviews plays an important role in psycho-oncological research and has done so ever since Glaser and Strauss's inaugural study in San Francisco in the 1960's on dying in hospitals (Glaser \& Strauss, 1965). Apart from this, the coping concept has its origin in stress theory, research on coping in the context of life events, and psychoanalytical theory of defence mechanisms (Koehler, Koenigsmann, \& Frommer, 2009; Livneh \& Martz, 2007; Snyder \& Dinhoff, 1999). The most influential theory of coping and stress management today has been developed by Lazarus and Folkman (1984). This model emphasises that coping processes are situa- 
tional and conceptual. It states a distinction between problem-focused and emotion-focused efforts. Problem-focused efforts of coping should help to solve or adapt to the problem by collecting information, acting and non-acting. Emotion-focused efforts of coping intend to reduce or to regulate the emotional stress inherent in the situation (e.g., acceptance, cognitive or behavioural avoidance).

The interest in subjective narrative representations of suffering from disease and of personally dealing with and working on it (Strauss, Fagerhaugh, Suscek, \& Wiener, 1985) as well as in qualitative research on patients' perspectives in general has grown in the last years in the fields of oncology (Loprinzi, 2003), psychology (Rennie, Watson, \& Monteiro, 2002), psychotherapy research (Frommer \& Rennie, 2006) as well as in medicine in general (Greenhalg $\&$ Hurwitz, 1998). Different methodological concepts were developed for exploring subjective illness narratives and coping processes. Quantitative questionnaire-based methods focus on generalizability of results whereas interview-based methods are particularly suited to gaining more information in nonquantifiable intrapersonal and interpersonal processes of feeling, thinking and meaningful interaction. They are not only explorative and useful for generating hypotheses, but also unique regarding their access to specific psychic and social phenomena. It is known that the degree of concordance of results generated with these two assessment approaches on the same research subject is different (Fischer-Kern et al., 2004), and thus, one of these types of study designs cannot be replaced by the other without significant loss of relevant empirical information.

However, hitherto only a few studies have been published in the field of research on adult leukaemia patients. As in other forms of cancer, results are complex, for example with regard to quality of life. Summing up, it can be concluded that having leukaemia leads to an existential insecurity which expresses itself at times in seemingly irrational forms of coping that are of high subjective evidence for the patients themselves, and which are influenced by the patients' life stories rather than by medical explanations (Friis, Elverdam, \& Schmidt, 2003, 2005; Koenigsmann, Koehler, Franke, \& Frommer, 2006a; Koenigsmann, Koehler, Regner, Franke, \& Frommer, 2006b).

While some studies address psychosocial variables in relation to the disease's progress (Tschuschke et al., 2001), the focus of our study lies on the survivors' psychosocial adaptation including integration of disease-related experiences as part of their autobiographical narration. The clinical significance of this biographical grounding comes into view through the determining function of subjective illness concepts in psychotherapy with cancer patients. One type of survivors' subjective adaptation is the so-called trajecto$r y$ of suffering (TOS) from the disease. TOS is a mi- crosociological concept that can be used for empirical research on how cancer patients adapt to the mental shock situation after diagnosis. Process structures in general are mental ordering principles of life history. Schütze differentiates four elementary process structures: (1) institutional expectation pattern of the life course, (2) biographical action schemes, (3) creative metamorphoses of biographical identity, and (4) TOS (Riemann \& Schütze, 1991; Schütze, 1981, 2007a, 2007b). According to Schütze TOS is one of the process structures of human biography and is defined as sequences of events and activities that arise and which cannot be grasped in terms of intentional actions or controlled by them. TOS is characterised by being no longer able to organise one's own life in an active way (Betts, Griffiths, Schütze, \& Straus, 2007). TOS allows the systematic description of the processes involved in a stepwise loss of social normality towards a situation of anomie, which means "normlessness" in terms of the breakdown of social bonds between an individual and his community, including fragmentation of social and personal identity, and rejection of self-regulatory values.

The aim of our study is to examine the concept of TOS, exemplified with the life-threatening experience of suffering from acute leukaemia in terms of biographical grounded coping processes. Under this perspective our interest is situated in the recognition of the coping strategies of the study participants, in particular what types of thoughts, feelings and fantasies have occurred, and which of these ideas were felt to be helpful to escape the fatal "from-bad-to-worse" dynamics of the leukaemia TOS, and to regain control and self-confidence. Using a qualitative approach, based on autobiographical narrations of leukaemia survivors, we will challenge whether the dichotomic distinction between the problem-oriented and emotion-driven strategies currently used in coping research are sufficient to grasp all relevant processes dealing with the integration of the disease into the life story of cancer survivors.

\section{Material}

\section{Participants}

The current study investigates the life stories of 17 acute leukaemia survivors (8 male, 9 female). The age range was from 24 to 73 . According to Kornblith (1998), survivors of acute leukaemia have neither been sick nor undergone treatment for at least one year. Following this definition, people who had had no treatment for a minimum of one year were included in the study. All participants underwent written and informed consent as approved by the Internal Review Board. They were recruited by the Department of Haematology and Oncology at the University Hospital of Magdeburg. The first author of this paper conducted all interviews. 
Table 1. Age, socio-demographic data and length of interview

\begin{tabular}{|c|c|c|c|c|c|c|}
\hline $\mathrm{Nr}$. & ID & Age & Sex & Education (highest degree) & Current profession & $\begin{array}{c}\text { Interview } \\
\text { length } \\
\text { (in min.) }\end{array}$ \\
\hline 1 & 001-UE & 58 & Female & Technical School & Early retiree & 80 \\
\hline 2 & 002-UE & 25 & Female & Secondary Modern Diploma & Unemployed & 144 \\
\hline 3 & 003-UE & 64 & Female & 8th Grade & Pensioner & 57 \\
\hline 4 & 004-UE & 63 & Female & 8th Grade & Pensioner & 70 \\
\hline 5 & 005-UE & 25 & Female & Secondary Modern Diploma & Telephone operator & 118 \\
\hline 6 & 006-UE & 54 & Female & Technical School & Company group-manager & 140 \\
\hline 7 & 007-UE & 41 & Female & 10th Grade & Office worker - Police & 160 \\
\hline 8 & 008-UE & 71 & Male & 8th Grade & Pensioner & 119 \\
\hline 9 & 009-UE & 61 & Male & 8th Grade & Taxi driver & 53 \\
\hline 10 & 010-UE & 43 & Male & 9th Grade & Building worker & 63 \\
\hline 11 & 011-UE & 25 & Female & Advanced Technical Certificate & Unemployed & 99 \\
\hline 12 & 012-UE & 24 & Male & Secondary Modern Diploma & Apprentice & 102 \\
\hline 13 & 013-UE & 73 & Female & 8th Grade & Pensioner & 127 \\
\hline 14 & 014-UE & 51 & Male & 10th Grade & Early retiree & 145 \\
\hline 15 & 015-UE & 39 & Male & 10th Grade & Unemployed & 116 \\
\hline 16 & 016-UE & 64 & Male & 8th Grade & Retiree & 176 \\
\hline 17 & 017-UE & 50 & Male & 8th Grade & Long-distance truck driver & 157 \\
\hline
\end{tabular}

\section{Depiction and analysis of autobiographical narrative interviews}

We conducted autobiographical narrative interviews (ANI), which were recorded on tape with the participants' informed consent and transcribed according to guidelines developed by Mergenthaler and Stinson (1992). In contrast with quantitative research or fully structured interviews, the narrative interview approach allows the participants to openly describe and explain their thoughts and emotions and permits our multidisciplinary working group the best possible search for variability and different phenomena of the above research subject.

All names and locations were anonymised through pseudonyms. Speech dialects are depicted, to make the background of the lived-in world clear.

Each ANI begins with an open invitation to the participant to tell her or his life history (e.g., "Please tell me your life story. You can take all the time that you need. I will listen to you and make some notes for myself"). This invitation is oriented to the participant's autobiographical memory and designed to generate an autobiographical narrative. The participant's extempore narration constitutes an unplanned spontaneous narrative, which is not influenced by previous preparation; it dismisses "the standardised version" of a repeatedly told story.

The very low level of structuring of ANI facilitates the reproduction of the inner form of the participant's sedimentation of experience with respect to occurrences in the life course. The participant indicates the end of the narrative by a so-called "narrative coda" (e.g., "That's all"). This signals to the researcher that he can start with the narrative questioning part. The interviewer prods the participant to repeat vague or even unclear aspects of the concatenation of events and to dwell on topics just alluded to but not further developed. The researcher can also formulate questions of research interest not touched in the main story line of the participant (e.g. "Seen from today's perspective: How did you experience yourself as a patient in the hospital?" or "Were there moments during the illness in which you were highly uncertain and no longer knew what to do next?"). And then further questioning follows.

The data analysis was carried out along the proposed rules by Schütze (1981, 2007a, b). Relevant aspects of quality criteria were published elsewhere (Steinke, 2004).

The ANI analysis differentiates between single case analysis and cross-case analysis. Through the single case analysis (steps are description of content, analysis of text type, and so-called analytical abstraction), provisional categories are developed (e. g., dealing with feelings, own theories of aetiology, previous experience of illness). With the evaluation of additional interviews in the cross-case analysis, the established categories can be verified, complemented and new connections deduced in the empirical data involved. Finally, the common patterns of social and biographical processes identified are integrated into a theoretical model. During the research process interviews and findings were presented and critically discussed iteratively at periodic meetings of the research team.

\section{Results}

The presentation of the results is structured according to two main exploratory aspects: First, how acute leukaemia triggers TOS and how those TOS can be 
characterised; and secondly, how individuals handle the shock and trauma of being threatened by death and manage to return to normal daily life. This encloses the question of which feelings, experiences, ideas and fantasies the patients subjectively found to be helpful to cope with the TOS.

\section{Entering the trajectory of suffering: First symptoms and diagnosis}

We first address the unfolding of the life-threatening leukaemia TOS: All participants suffered from unspecific symptoms and/or suspicious blood tests before the diagnosis of acute leukaemia was executed; e. g. $\mathrm{Mr}{ }^{*}$ Hasel described that he felt "weak," as though coming down with a cold. Following this interpretation of the symptoms, he took a bath. He "passed out," and regained consciousness in hospital. The family doctor, notified of $\mathrm{Mr}$ *Hasel's collapse, referred him to hospital, where "they found it out."

The quote from the interview with Ms *Birke shows how the announcement of the diagnosis can lead to an abrupt fragmentation, loss of control and psychic traumatisation through the disease:

Said to me, "yep: you have leukaemia" I think man, another one, another slap in the face, yeah, that's leukaemia! Great! I think "no, that's enough", then I stood up, "Ms *Birke, I'm not finished yet", I said "leave me alone, just leave me alone", [...] I started to cry, but I didn't care, okay? "What's the matter?" I said "Leave me alone! Don't touch me!" She said "you don't have to be so aggressive", I said "I'm not aggressive, I'm calmness itself just don't touch me".

For $\mathrm{Ms}{ }^{*}$ Birke, the diagnosis appears abstract, unreal and cannot at first be completely taken in. At the same time, the instability of the actual illness situation makes quick medical action imperative; the prognosis worsens with every day without treatment. Between the diagnosis and the start of therapy, participants are given almost no time to realise what is happening or to converse and reflect about it with their families. They often enter the hospital with the apparently harmless symptoms of a common cold. Once there, they suddenly become seriously ill individuals in a completely foreign environment. During the first cycle of therapy, they start to begin to understand gradually by step their life-threatening situation:

I just turned off and thought, who knows what's going to come, maybe it's all over, the thought comes automatically [...]. After seven days, after I got Chemo, after seven days my hair fell out, all my hair, and I really noticed how weak I was [...]. After the first Chemo I had a [...] phase, I was allowed to go home for eight days. I felt so bad I thought, "when the second time is as bad as that I'm gonna slit my wrists!". I couldn't take it anymore, I was just worn out [...]. I just kep' thinking, "are you gonna make it? Or not?" (Mr*Fichte).
This text passage also clearly shows the burden of therapy side effects on the participant. It shows that the interviewee feels that he would rather die than go through such a torture again. The examples of Ms ${ }^{*}$ Birke and $\mathrm{Mr}{ }^{*}$ Fichte show how the leukaemia TOS becomes the dominating process structure of their autobiographical narration. The diagnosis pulls them out of their everyday life (from healthy, strong and with plans for the future to seriously ill, weak and facing death) and thus suspends their action competences. The severe side effects of the therapy intensify the leukaemia TOS development. Their own body becomes estranged and is perceived as a threat (Hefferon, Grealy, \& Mutrie, 2010). Subsequently, Ms ${ }^{*}$ Birke and $\mathrm{Mr}{ }^{*}$ Fichte behave in a reactive manner and feel directed by external circumstances. Influencing the further development by one's own efforts is not imaginable for them, their orientation in life becomes increasingly despondent (Betts et al., 2007; Riemann \& Schütze, 1991). These all-overshadowing events lead to the situation where the study participants lose trust in themselves and the helpful relationship with their partners. Some of them develop fantasies about choosing suicide over painful therapy, view themselves as incapable of everyday actions, and feel as if they are non-reliable from their partners' perspective. In addition, they feel incapable of engaging in social relationships or taking care of themselves. They mistrust their own abilities, oscillating between denial of their factual situation and feelings of hopelessness.

\section{Coping with trajectory of suffering}

The inability to act in everyday affairs and in the framework of longer lasting biographical provisions, and the feeling of being a stranger to oneself as well as to one's social and spiritual environment force the participants to radically redefine their life situation. Among all participants of our study, there is a discrete moment identifiable in the interviews where the situation changes again after the climax of the TOS development. From this point onwards, they begin to attempt to defend themselves against death's grasp and exert control over their trajectory. Impulses to cope with the leukaemia TOS can be favourably influenced by felicitous events or experiences or by compassionate and helpful individuals and their actions. This special kind of survivor's coping by a reflective entering one's own illness story helps the participants to adjust to their illness and develop new perspectives.

According to our research interest, we focussed on those parts of the interviews, in which the survivors felt in the phase of suffering most and tell what helped them find their way back into normal life. The quotations presented from the interviews are examples. For each category one quote was selected which suited best to the respective category. 
Personal meaningful nourishments (Mr *Fichte, Mr *Tanne, Mrs *Esche, Ms *Eiche). One of the categories we identified is the participant's focus on specific nourishments. Although dietary advice is given by physicians in order not to jeopardise the successes in treatment (Denmark-Wahnefried, Aziz, Rowland, \& Pinto, 2005), for example not to eat unwashed and unpeeled fruit, we could observe that certain food was of particular importance for the study participants. One reason might be that the participants could exercise control over this aspect of their situation, while doctors and nurses determined and controlled most other daily life processes. Nourishment thus represents a comforting experience of regaining action capacity and everyday normality. Moreover, feeding seems to be an opportunity to strengthen the weakened and diseased body. By this, the participants felt like active protagonists in the healing process. Thirdly, feeding the participant was a way for the relatives to express their care, sympathy and concern. Fourthly, the interviewees experienced homemade food as something from outside the hospital world, and thus saw it as an almost magic source of providing healing power. The following quotation shows this topic exemplified by a conflict between $\mathrm{Mr}$ *Fichte and his doctor regarding autonomy, represented by an egg from the henhouse of the interviewee's home:

I had no appetite, so I said "ya know what, when you come, then you bring a whisked egg, with sugar, whisked" and I drank that [...]. And one time the doctor, he came to me and said "what's that you're drinking?" I said "Doctor, raw egg," "My, my, you're not allowed to do that," "why not?," "there could be salmonella in it, I said 'there ain't any," said "my chickens at home are all healthy, we don't have salmonella," "you don't know that, uh, you didn't know about your own illness either," I said "our animals are vaccinated [...] there's nothin' in there, don't worry" and I kept doing that and it was good for me, wasn't it? Cause it's healthy, isn't it?

This illustrates the participant's fundamental conviction that his own ecological niche at home contains the way to cope with his illness. For the doctor, a raw egg is dangerous and detrimental as it can cause salmonella. However, $\mathrm{Mr}$ *Fichte is firmly convinced that an egg from his own chicken can help him to regain health. From his point of view, a body weakened by chemotherapy regains strength through healthy, domestic products. This conviction allows him to regain a certain feeling of mental and emotional control over the illness's progression and his own body. In terms of the types provided by Lazarus and Folkman (1984), this category is mainly about problem-focused coping, in particular representing a suitable strategy for physical strengthening. However, the assignment to this type of coping is not completely satisfactory, because personal meaningful nourishments are indeed subjectively problem- oriented, but not from the objective perspective of the medical staff. Thus, emotional and irrational aspects are essential, too.

Challenging experiences with significant others (Mrs *Erle, Mr * Lärche, $\mathrm{Mr}$ *Ulme, Mrs *Linde). Another category derived inductively from the narrations captures the tendency of significant others to shape interpersonal conflicts and thus to provoke experiences that act as revelations. Those struggles can exert a formative influence on the leukaemia sufferers. The study participants evaluated those experiences in the interview, as the following example depicts.

Mrs *Erle, like many others, was not allowed to eat all kinds of food. For fear of making a mistake, she asked one of the nurses if she could eat a tangerine. Mrs *Erle had what she called a "really stupid experience" with the nurse. The occurrence made her so indignant that she felt compelled to fight against her illness.

[...] so I asked the nurse if I could maybe eat a [...] tangerine and she said to me "I'd eat it if I were you, you never know how long you'll be able to," I thought, "what's her problem? She must be crazy" and I said, "I'm gonna get well here!," and so I thought, "just for that I'm not [...] gonna eat it at all! [....] I'm gonna eat it later, cause there's gonna be a later," I knew I'd make it, deep inside! Not always in my head, but inside, I like protested inside, how could she say something like that to someone with cancer, "you don't know how long you'll be able to do that."

Mrs* Erle reacts angrily. She is bewildered about the non-empathic utterances of the nurse. What follows are her remarks on the development of resistance and fighting spirit (Grulke \& Bailer, 2007) against the disease. In our interpretation, her anger seems to be not only an additional burden, but also a challenge, helping her to conceptualise ideas to recover from her leukaemia in order to show the nurse, that she will be able to enjoy tangerines in the future, too. The example shows that interpersonal struggles and conflicts can help the patient to resist leukaemia and thus help to solve the problem of health threat. In addition to these problem-focussed aspects in terms of Lazarus and Folkman emotional aspects play an important role, too, because having arguments often is triggered by emotions like anger, anxiety, or desperation.

Courage to persevere (Ms ${ }^{*}$ Linde, Mrs *Ahorn, Mr *Pappel, Mr*Kastanie). The third category we have found is already described in the coping literature on fighting spirit (Grulke \& Bailer, 2007). Despite the fact that Ms ${ }^{*}$ Linde is aware that medical treatment plays a major role in the success of healing, she is convinced that if she believes in herself and has the courage to face the challenges of the disease, her chance of healing will increase essentially. Complementarily she supposes that if she gives up, she will lose the fight against the disease: 
But I said to myself, that's the only way you can maybe make it, if you don't think about it all the time and, uh, when you keep your guts, and I heard, it doesn't just depend on doctors, uh, whether you get better, they've got a lot to do with it of course, maybe the most important part, but it depends on yourself, too. That you get up the courage to fight, and that's what I tried to do.

Similar to the two categories above, this category represents problem-focused aspects as well as emotion-focussed ones. On the one hand, the interviewees told that it helped them to conceptualise leukaemia as a problem that could be solved by their own will and efforts. On the other hand, it is overt from an objective perspective that these feelings occurred in situations characterised by a maximum of helplessness, powerlessness, and surrender.

Family Support (Mr ${ }^{*}$ Hasel, Ms ${ }^{*}$ Kiefer, Mr *Weide, Mrs *Esche). As known from studies on family support and social support, interpersonal relationships play a significant role in coping behavior (Given, Given, \& Kozachik, 2001). Family support does not only provide important assistance for the participant throughout the entire course of therapy, it also acts as a link to the outside world and thus presents a kind of communicative normality between the secluded participant and the "healthy" world of normal everyday affairs outside. However, not only does the family care about and show concern for the participant, she or he is in turn concerned about the family's welfare, how it manages on a daily basis and suffers from her or his absence. This is especially true when the family's existence depends on the patient's health. $\mathrm{Mr}{ }^{*} \mathrm{Hasel}$ owns a taxi business into which he pours great energy to develop and therefore does not want to abandon. His efforts to keep his business going strengthened him:

We're not gonna let ourselves down! that's what distracts you a little and when you achieve something you get stronger [...]. If you fight for something a long time then you don't give it up so easily [...] that's what I thought, see, the will, "it's gotta go on" and I wanted to be independent, that was probably what kept me going, and I was ambitious, see?! — up 'til, you could say up 'til now.

As the small taxi company was a family business, $\mathrm{Mr}{ }^{*}$ Hasel was able to rely on his wife during his illness. She managed the company during his absence ("was busy, had to run the business, you know"). This example not only reveals the importance of his family's economic existence to $\mathrm{Mr}{ }^{*} \mathrm{Hasel}$, but also the enormous challenges which had to be met by the family. Both aspects confirm the mental and emotional importance of a stable family environment for coping with leukaemia TOS. Hence, according to our view and to the proposed definition by Lazarus and Folkman, this category can rather be assigned to emotion-focused coping, because feelings of being part of a healthy and positively developing whole are the core of the text passages assigned to it.
Dramatic family events (Mrs *Buche, Mrs *Eibe). An additional category found to be crucial in the narratives has to do with incisive family events during the illness that influence the participant to redefine their current life situation. Such an event is exemplified by the tragic death of Mrs *Buche's grandchild, an event she described as one of many "strokes of fate:"

anyway, I sat down on my bed, all of the sudden the door opened and black-six figures dressed in black came in [...] and my grandchild, he flung himself around my neck and said "grandma, my brother is dead" [...] now that was a shock! I lay down on my bed and put my head under the covers I-I couldn't believe it [...]. Everything was just terrible and then I wasn't allowed to go to the funeral, they didn't let me [...] that time when that was going on with my grandchild, this and that, "why * $M$ ? why not me?" It was really bitter.

Through the loss of her beloved grandchild, the seriousness of Mrs *Buche's own illness receded into the background, and the ill fate and loss of a young family member took precedence over everything else. The situation was aggravated by the fact that Mrs ${ }^{*}$ Buche was too ill to take her leave of her grandchild at the graveside. In addition, her severe suffering is intensified by her mental and emotional comparison of the disproportion in her and her grandchild's life expectancy. Her utterances gain transcendental overtones of theodicy: Why can there be the obvious injustice to let the child die and the grandmother live? From Mrs *Buche's lengthy description of her relationship to the deceased (weekly cemetery visits, conversations with the deceased at the grave, refusal to wear mourning), and visiting the grave, can be interpreted as symbolizing these questions. She feels she has a legacy and responsibility to live, handed down to her by her beloved family member who had to die so very early.

The case with Mrs *Eibe was something different. She told of a happy event in their family: the birth of her grandchild. Because the grandchild is not allowed to visit Mrs *Eibe in hospital, for her it became crucial to be healthy so that she can embrace her grandchild. Although both the examples presented of dramatic family events are completely opposing, they showed that good fortune as well as great tragedy could have the effect of changing the focus from being suffering from an sinister, unswayable and dangerous disease to other significant and touching life events. In our view this category could be rather assigned to emotion-focused coping in the sense of Lazarus and Folkman.

Dreams (Ms *Birke, Mr *Kastanie, Ms *Kiefer, Mrs *Erle). Since Freud's Interpretation of Dreams (Freud, 1900), dreams are often regarded as symbolically meaningful occurrences: as revealing definitions of a deeper sense of the current life situation or as prophecies. Accordingly, they can have effects on the 
dreamer and can influence her or his actions. The most dramatic dreams reported in our study were those described by Ms *Birke. Her dream could be identified as a trigger of a specific coping strategy and was characterised by a high degree of details. She dreamed in a situation of suffering from severe side effects and losing the will to survive at the beginning of therapy because of a fungal infection:

[...] so I thought, I just don't want to anymore! I thought, I don't want to wake up in the morning, I thought to myself, that went through my head, I couldn't say anything because of the fungus everywhere, I don't want! to get up! anymore! don't wake up anymore.

During this period, Ms ${ }^{*}$ Birke dreamt of entering the basement of a house situated in a dark forest. There she met black-clad schoolchildren with smooth black hair and nothing but black eyes in their faces. A woman who looked similar to the children screamed, "Catch her." In panic, the dreamer ran away into the forest, followed by these eerie creatures. Yet:

They got me anyway! They got me! Those hussies! All of them on top of me! And then I, I pushed them all away! And got up, and in that second I woke up [...] I was really loud, in the room [...] that dream! It was horrible, I was sweating non-stop!

In this situation $\mathrm{Ms}{ }^{*}$ Birke reported her dream to a nurse who interpreted it as both the cancer's attack on Ms *Birke and her defence against this attack. The interviewee told that she could identify with this interpretation of the nurse and remembered her mother's "prophetic" words:

[...] "you've got to fight, fight, fight" [....] "how am I supposed to do that?" Well? "Well! I can't tell you how! You'll learn it" and then I had that dream, right? Then I knew what fighting was!

Unlike, for example, the case of a broken leg, most leukaemia patients cannot pinpoint the origin and circumscriptive locus of their disease. Because of the complex haematological pathophysiology and the quasi-invisibility of the disease their assumptions are vague, unclear, and without concreteness. The capacity to dream allows concretizing both threats and healing fantasies emanating from this situation. Her dream helped $\mathrm{Ms}{ }^{*}$ Birke to regain belief in her own healing powers. Her ability to thrust back cancer within the finite province of the dream meant for her that she would also be able to take up the battle in reality, and that she would be able to take control over her life and not allow cancer to determine it. In order not to deviate from the new course of action, she sought diversion through contact with her peers:

[...] and then I sort of blocked everything out, took care of the others and then I felt better [...] I always had someone to talk to [...] and I was never really fully conscious of my sickness, I didn't give a damn, I didn't care about it, you gotta make it, [...] and go home, call it a day.

In some interviews, dreams were reported as occurring during the first weeks of therapy or following a traumatic experience, such as the sudden death of a fellow patient as $\mathrm{Mr}{ }^{*}$ Kastanie says, for example, or a painful medical procedure (injection, Ms ${ }^{*}$ Kiefer) respectively an unpleasant remark from one of the hospital employees (Mrs ${ }^{*}$ Erle). Such experiences, indirectly or in a veiled manner, seemed to remind the study participants of their own proximity to death.

The categories identified show aspects of both problem-focused and emotion-focused coping strategies. The category Dreams illustrates best the difficulties to assign these categories exhaustively to one of these types or the other. On the one hand dreaming encloses the handling and solving of conflicts and problems in a virtual space; on the other hand, dreams are an effective possibility to express feelings and concerns-even those which are suppressed when people are awake.

\section{Discussion}

The aim of our study was to conceptualise leukaemia survivors' coping processes using the microsociological concept of TOS. The results show firstly, that coping processes are determined by biographical predefined subjective illness concepts about cancer. These concepts are related to biographical experiences in everyday life before cancer diagnosis especially those dealing with critical episodes. Secondly, cancer survivors undergo their own, subjective cancer experience, high impact and everlasting "like an old handbag. It is sometimes visible or not, sometimes you seem to forget where it is, but this fear, your handbag, you will never lose it. It stays with you for a lifetime." 1 As a consequence of our study we assume that not only in cases with negative prognosis, but also in cases with complete remission, the experiences related to leukaemia remain a dominant and persistent threat that overshadows the whole future life of the affected persons.

The participants in our study showed different coping strategies as a reaction against the vicious circle of losing their psychic balance triggered by leukaemia: Personal meaningful nourishments represent an area where participants could feel themselves to be agents. Although their fate lies in the doctor's hands, and they must be able to rely on the doctor's competence, consumption of special nourishment not only offers a feeling of well-being but also of actively contributing to one's own healing. Dreams and challenging experiences with significant others confront the survivor with the possibility of her or his

\footnotetext{
${ }^{1}$ Quotation from a leukaemia patient not included in this study.
} 
own death. Realising the high probability of a fatal outcome galvanises them and triggers a combative stance against the disease. Family support, dramatic family events and the participant's courage to persevere help them to relinquish day-to-day worries and concentrate on the healing process.

Although all participants survived their disease, leukaemia still took up a predominant position in their autobiographical narratives. This is most evident in the fact that they mentioned the period before falling ill with acute leukaemia only briefly, whereas they presented occurrences from the time of the diagnosis in detail and partly with verbatim doctor-patient conversation quotations. Moreover, hardly any study participant was able to recount her or his biography in chronological order. In most cases, events related with leukaemia were predominantly told. All this leads to the assumption that none of the participants was fully able to integrate the disease into their biography up to the time of the interview. Acute leukaemia is therefore still a dark shadow over the lives of all study participants, regardless of how long the treatment has been over, or whether the survivors were male or female. One of the reasons may be that the risk of relapse was not entirely excluded at the time of the interview.

Even after the end of treatment, leukaemia is an important biographical topic in our interviews. This becomes evident from reports showing that aftercare consultations lead to re-traumatising experiences (Schmitt, Singer, \& Schwarz, 2003). Thus, cancer is not psychic trauma of limited duration. The cancer sufferers interviewed in our study, even though they were cured from a medical point of view, did not completely reach the posttraumatic stage (Cordova, 2008). Enduring posttraumatic stress was caused by the "serious current threat" (Ehlers \& Clark, 2000) the study participants had to cope with. However, indications of posttraumatic growth, as described by Hefferon et al. (2010) can be detected especially among the female participants by applying the body as a kind of tool or barometer in terms of being experienced and competent to indicate positive versus negative states of the whole self.

We identified emotion-focused and problemfocused coping strategies in both women and men. The results, however, tentatively indicate that women could be more prone to emotional coping, while men could be more prone to problem-orientation. Differences between the sexes, such as conscious and healthier lifestyles for women and recovery of physical strength for men, were found. Woman and men share a strong desire for normalisation, and integration into everyday life, and the desire for distance from the hospital atmosphere. The regular after-care for women and men involves both stressors as well as calming measures to check their health.

Studies conducted by other authors confirm our results regarding the mediating role of biographyrelated factors and patients' self-concept for coping with illness (Xuereb \& Dunlop, 2003). Recurring appraisals of personal meaning of life, attitudes toward death, re-evaluation of life goals, and integration of stressful events into a coherent autobiography become significant concerns during the course of a lifethreatening illness (Vehling et al., 2011). In discussing these results many authors (e.g., Snyder \& Dinhoff, 1999) follow the model of Lazarus and Folkman (1984). According to their definition, coping is a constantly changing cognitive and behavioral effort in order to manage specific demands. These efforts can demand or exceed the capabilities of the particular person to a certain extent. In this context Lazarus and Folkman regard coping as functional behaviour. Thereby they differentiate between problem-focused and emotion-oriented coping. Problemfocused coping involves the active solution of the particular problem or the encumbering situation, whereas emotional coping aims at modulation or avoidance of particular emotions. The point in doing so is to change the condition perceived as burdensome and to alleviate stress emotions (e.g., fear or depression). In addition to Lazarus and Folkman's comprehension of coping as functional behaviour, Koehler et al. (2009) focus on the essential coherence between patients' subjective concepts of illness and coping with illness. The particular concepts of illness lead to specific defence strategies and coping behaviour styles. All these coping efforts should be understood as biographical grounded conscious and unconscious regulation efforts (Koehler, Dogan, Koehler, Heine, \& Frommer, 2011a; Koehler et al., 2011b).

According to Lazarus and Folkman's classification of problem-focused and emotion-focused coping strategies, the six categories that were found can be assigned as follows: "meaningful personal nourishments," "challenging experiences with significant others" and "courage to persevere" might be assigned to problem-focused coping because they provide the means of active influencing the physiological treatment as well as mental recovery. They counteract to the weakening of the body by chemotherapy and the resulting threat of self-abandonment. The categories "family support" and "dramatic family events" are closer to emotion-focused coping strategies. They provide a part in everyday life and a substitute for the concern about oneself. No category found can be unambiguously assigned to problem-focused or the emotional group of coping styles, because both rational and emotional aspects are relevant throughout.

The category "dreams" has been identified as an important resource for our participants. Problemfocused and emotional aspects might have a certain meaning in producing dreams, but they are subordinate. Thus, this category shows best that coping is not only triggered by rational and/or emotional motifs, but also by other forces. We propose to name this kind of coping behaviour the creative one. Dreams can be the basis for a problem-focused as well as an emotional coping, like every other subjec- 
tive representation, too. Moreover, dreams demonstrate that creative acts can be a coping resource themselves. In our definition: Creative phenomena (e.g., dreams) refer to a mental activity in which the person is not directly dealing with the problem and not trying to change emotions. Rather, a person uses it to obtain a vital subjective regulation (e.g., positive feelings or impulses for action regulation). Dreams and other creative activities (e.g., singing, dancing) can be a starting basis or stimulus for following sensations or events. Moreover, through the dreamer's interpretation of his dreams, dreams gain a functional character.

Participants were recruited through psychooncology services and knew the focus of the study to be leukaemia, so one of the limitations of the study is a presumption through the recruiting process. Although participants were asked to give an unselective account of their entire biography, a deliberate selection of leukaemia-connected themes cannot be excluded. Another limitation could be the small sample compared to the age ranging from 24 to 73 . Furthermore, no distinction has been made between acute myeloid leukaemia (AML) and acute lymphoblastic leukaemia (ALL). Instead, both were subsumed under the term acute leukaemia. AML as well as the ALL were assessed as potentially fatal diseases with similar coping efforts. Lastly, the wide span of one to ten years after treatment could be regarded as a limitation. Nevertheless, similarities emerged between the narrations of participants whose end of treatment had been only a few years ago and of those lying ten years in the past.

In summary, our main concern was to point attention to cancer survivors' mental regulation, taking account of their biographically grounded coping processes by use of the autobiographical narrative method. Due to the possibility that ANI allows for freely telling the life stories of our research participants, we gained an innovative and deep insight into the biography and the life-threatening experience of suffering from acute leukaemia. This and the systematic comparison of survivors' coping efforts allow a detailed understanding of the biographical grounding of their strategies.

Finally, we would like to summarize for daily clinical practice. Our results imply for clinical practice that successful coping strategies not only develop based on objectives, but also on subjective evaluation mechanisms (Koehler et al., 2009). Nourishment for example is not known for an objective support of oncological healing processes (Gardner et al., 2008). Nonetheless, from patients' perspectives it can be a plausible coping strategy to influence the treatment course and quality of life. It must be taken into account by oncologists that the patients' preferences for treatment, the patients' compliance and their coping strategies are affected by their subjective concepts of illness (Koehler et al., 2009). Because survivors' respect and fear of cancer is stable over time in view of their remission status, it is vital that the medical staff should recognize and discuss the individual needs, ideas and feelings of the persons affected. Early identification of survivors' subjective perceptions of the cancer experience might improve quality of life (Smith et al., 2011). The findings may also be integrated in medical and psycho-oncological training. Especially the aspect of creativity should be involved in psychotherapeutical interventions.

\section{Acknowledgments}

This study was supported in part by the German José Carreras Leukaemia Foundation (Grant Number DJCLS-R05/34pf).

\section{References}

Betts, S., Griffiths, A., Schütze, F., \& Straus, P. (2007). Biographical counselling: An introduction. Module 0. INVITE Biographical counselling in rehabilitative vocational training - Further education curriculum. Available: http:// www.biographicalcounselling.com/download/0.pdf

Buechner, T., Berde, W. E., Haferlach, C., Haferlach, T., Schnittger, S., Mueller-Tidow, C., ... Hiddemann, W. (2009). Age-related risk profile and chemotherapy dose response in acute myeloid leukemia: A study by the German Acute Myeloid Leukemia Cooperative Group. Journal of Clinical Oncology, 27(1), 61-69. doi.10.1200/JCO.2007.15.4245.

Cordova, M. (2008). Facilitating posttraumatic growth following cancer. In S. Joseph \& A. Linley (Eds.), Trauma, recovery and growth: Positive psychological perspectives on posttraumatic stress (pp. 185-206). New York: John Wiley.

Demark-Wahnefried, W., Aziz, N., Rowland, J., \& Pinto, B. M. (2005). Riding the crest of the teachable moment: Promoting long-term health after the diagnosis of cancer. Journal of Clinical Oncology, 23(24), 5814-5830. doi: 10.1200/JCO.2005.01.230

Ehlers, A., \& Clark, D. M. (2000). A cognitive model of posttraumatic stress disorder. Behaviour Research and Therapy, 38, 319-345. doi: 10.1016/S0005-7967(99)00123-0

Estey, E. H, \& Kantarjian, H. M. (2005). Therapy for acute myeloid leukemia. In Hoffman R., Benz E. J. \& Shattil S. J. (Eds.), Hematology, basic principles and practice (pp. 10991112). Philadelphia: Elsevier Inc.

Fischer-Kern, M., Leithner, K., Voracek, M., Löffler-Stastka, H., Jandl-Jager, E., \& Springer-Kremser, M. (2004). Selfreport versus interview data of women's subjective theories of illness: concordance and predictive validity in a psychosomatic-gynecological liaison service. Journal of Psychosomatic Obstetrics and Gynaecology, 25(3-4), 235-245. doi: 10.1080/01674820400024455

Freud, S. (1900). The Interpretation of Dreams. The Standard Edition of the Complete Psychological Works of Sigmund Freud.

Friis, L. S., Elverdam, B., \& Schmidt, K. G. (2003). The patient's perspective: A qualitative study of acute myeloid leukaemia patients' need for information and their information-seeking behaviour. Supportive Care in Cancer, 11(3), 162-170. doi: 10.1007/s00520-002-0424-6

Friis, L. S., Elverdam, B., \& Schmidt, K. G. (2005). Need of and desire for information by patients with acute myeloid leukaemia. Ugeskrift for Laeger, 67, 514-516.

Frommer, J., \& Rennie, D. L. (Eds.). (2006). Qualitative psychotherapy research: Methods and methodology. Lengerich: Pabst Science Publishers. 
Gardner, A., Mattiuzzi, G., Faderl, S., Borthakur, G., GarciaManero, G., Pierce, S., ... Estey, E. (2008). Randomized comparison of cooked and noncooked diets in patients undergoing remission induction therapy for acute myeloid leukemia. Journal of Clinical Oncology, 26(35), 5684-5688. doi: 10.1200/JCO.2008.16.4681.

Given, B. A., Given, C. W., \& Kozachik, S. (2001). Family support in advanced cancer. CA: A Cancer Journal for Clinicians, 51(4), 213-231. doi: 10.3322/canjclin.51.4.213

Glaser, B. G., \& Strauss, A. L. (1965). Awareness of dying. Chicago: Aldine.

Greenhalgh, T., \& Hurwitz, B. (Eds.). (1998). Narrative based medicine: Dialogue and discourse in clinical practice. London: BMJ Books.

Grulke, N., \& Bailer, H. (2007). "Fighting Spirit" gegen Krebs: Ein Schlüssel für längeres Uberleben? ["Fighting spirit" against cancer: A key to survival in cancer patients?]. $M M W$ Münchener medizinische Wochenschrift, 149(16), 35-36.

Hefferon, K., Grealy, M., \& Mutrie, N. (2010). Transforming from cocoon to butterfly: The potential role of the body in the process of posttraumatic growth. Journal of Humanistic Psychology, 50(2), 224-247. doi:10.1177/0022167809341996

Koehler, M., Koenigsmann, M., \& Frommer, J. (2009). Coping with illness and subjective theories of illness in adult patients with haematological malignancies: systematic revive. Critical Reviews in Oncology/Hematology, 69(3), 237-257. doi: 10.1016/j.critrevonc.2008.09.014

Koehler, K., Dogan, E., Koehler, M., Heine, V., \& Frommer, J. (2011a). Das Überleben der initialen Phase: Subjektive Krankheitsvorstellungen von Patienten mit akuter Leukämie zum Ende der stationären Erstbehandlung [Surviving the initial phase: Subjective theories of illness of patients suffering from acute leukaemia at the end of first inpatient treatment]. Zeitschrift für Psychosomatische Medizin und Psychotherapie, 57(2), 141-156.

Koehler, M., Koehler, K., Koenigsmann, M., Kreutzmann, N., Fischer, T., \& Frommer, J. (2011b). Beyond diagnosis: Subjective theories of illness in adult patients with acute myeloid leukemia. Hematology, 16(1), 5-13. doi: 10.1179/102453311X12902908411599

Koenigsmann, M., Koehler, M., Franke, A., \& Frommer, J. (2006a). Acute leukaemia in adults: Researching the patient's perspective. Leukemia, 20(2), 206-207. doi:10.1038/sj.leu.2404005

Koenigsmann, M., Koehler, K., Regner, A., Franke, A., \& Frommer, J. (2006b). Facing mortality: A qualitative indepth interview study on illness perception, lay theories and coping strategies of adult patients with leukemia one week after diagnosis. Leukemia Research, 30(9), 11271134. doi:10.1016/j.leukres.2005.12.016

Kornblith, A. B. (1998). Psychosocial adaptation of cancer survivors. In Holland J. C. (Ed.). Psycho-Oncology (pp. 223241). New York: Oxford University Press.

Lazarus, R. S., \& Folkman, S. (1984). Stress, appraisal and coping. New York: Springer.

Livneh, H., \& Martz, E. (2007). An introduction to coping theory and research. In Martz E., Livneh H. (Eds.), Coping with chronic illness and disability (pp. 3-27). New York: Springer.

Loprinzi, C. L. (2003). The art of oncology: When the tumor is not the target. Journal of Clinical Oncology, 21(9), Supplement, 1-128. doi: 10.1200/JCO.2003.01.205.

Mergenthaler, E., \& Stinson, Ch. (1992). Psychotherapy transcription standards. Psychotherapy Research, 2(2), 125-143. doi: $10.1080 / 10503309212331332904$
Rennie, D. L., Watson, K. T., \& Monteiro, A. (2002). The rise of qualitative research in psychology. Canadian Psychology, 43(3), 179-189. doi: 10.1037/h0086914

Riemann, G., \& Schütze, F. (1991). Trajectory as a basic theoretical concept for analyzing suffering and disorderly social processes. In Maines D. R. (Ed.), Social organization and social process: Essays in honor of Anselm Strauss (pp. 333357). New York: De Gruyter.

Schmitt, A., Singer, S., \& Schwarz, R. (2003). Evaluation of posttraumatic psychological problems in cancer patients. Onkologie, 26(1), 66-70. doi: 10.1159/000069867

Schütze, F. (2007a). Biographical analysis on the empirical base of autobiographical narratives: How to analyse autobiographical narrative interviews - Part I. INVITE - Biographical counselling in rehabilitative vocational training: Further education curriculum. Retrieved from http://www.unimagdeburg.de/zsm/projekt/biographical/1/B2.1.pdf

Schütze, F. (2007b). Biographical analysis on the empirical base of autobiographical narratives: How to analyse autobiographical narrative interviews - Part II. INVITE - Biographical counselling in rehabilitative vocational training: Further education curriculum. Retrieved from http://www.unimagdeburg.de/zsm/projekt/biographical/1/B2.2.pdf

Schütze, F. (1981). Prozeßstrukturen des Lebensablaufs [Biographical process structures]. In Matthes J., Pfeifenberger A. \& Stosberg M. (Eds.), Biographie in handlungswissenschaftlicher Perspektive (pp. 67-156). Nürnberg: Sozialwissenschaftliches Forschungszentrum der Universität Erlangen-Nürnberg.

Smith, S. K., Zimmerman, S., Williams, C. S., Benecha, H., Abernethy, A. P., Mayer, D. K. ... Ganz, P. A. (2011). Posttraumatic stress symptoms in long-term non-hodgkin's lymphoma survivors: Does time heal? Journal of Clinical Oncology, 29(34), 4526-4533. doi: 10.1200/JCO.2011.37.2631.

Snyder, C. R., \& Dinhoff, B. L. (1999). Coping: Where have you been?. In Snyder C. R. (Ed.), Coping: the psychology of what works (pp. 3-19). New York: Oxford University.

Steinke, I. (2004). Quality criteria in qualitative research. In U. Flick, E. von Kardorff \& I. Steinke (Eds.). A companion to qualitative research (pp. 184-190). London: Sage.

Strauss, A., Fagerhaugh, S., Suscek, B., \& Wiener, C. (1985). The social organization of medical work. Chicago: Chicago University Press.

Tschuschke, V., Hertenstein, B., Arnold, R., Bunjes, D., Denzinger, R., \& Kaechele, H. (2001). Associations between coping and survival time of adult leukemia patients receiving allogeneic bone marrow transplantation. Results of a prospective study. Journal of Psychosomatic Research, 50(5), 277-285.

Vehling, S., Lehmann, C., Oechsle, K., Bokemeyer, C., Krüll, A., Koch, U., \& Mehnert, A. (2011). Global meaning and meaning-related life attitudes: exploring their role in predicting depression, anxiety, and demoralization in cancer patients. Supportive Care in Cancer, 19(4), 513-520. doi: 10.1007/s00520-010-0845-6.

Xuereb, M. C., \& Dunlop, R. (2003). The experience of leukaemia and bone marrow transplant: searching for meaning and agency. Psycho-oncology, 12(5), 397-409. doi: 10.1002/pon.648

Received July 22, 2012

Revision received September 10, 2012 Accepted September 26, 2012 